\title{
A imagem dos Tükúna no contexto de um trabalho antropológico: fotografias de Roberto Cardoso de Oliveira.
}

(Banco de imagens/Arquivo Edgard Leuenroth - Unicamp)

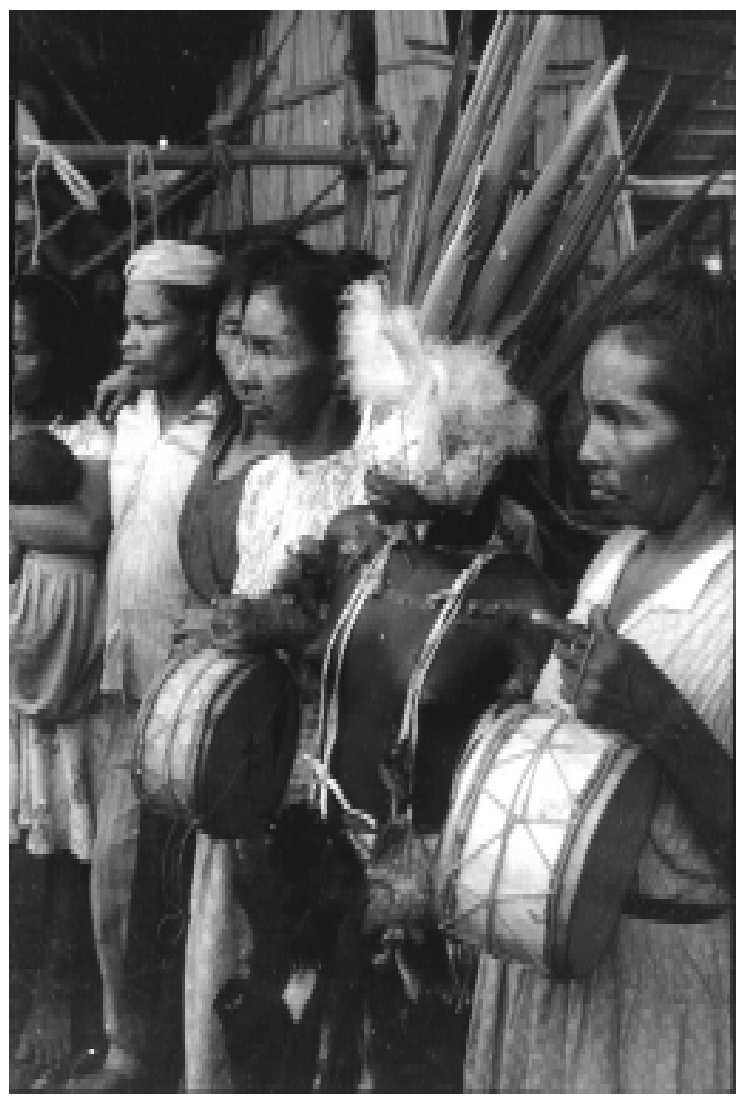

CADERNO DE FOTOGRAFIAS 


\section{Ritos de passagem}

As imagens da festa de "moça nova" que serão vistas a seguir (com exceção das três primeiras, tomadas isoladamente em dias subsequientes) foram feitas nos dias $25,26 \mathrm{e}$ 27 de abril de 1959 em Vera Cruz, pequena localidade situada entre os inúmeros igarapés do rio Alto Solimões, próximo à fronteira com Peru e Colômbia. A festa representa a ocasião ritual e social de máxima importância na vida Tükúna, quando a jovem púbere, em reclusão por cerca de três meses, é reintegrada como mulher (moça) na comunidade. Nesta festa, além da iniciação da "moça nova", um menino de dois anos e uma menina de oito anos, irmãos da "moça nova", passaram pela cerimônia de nominação, marcando, num caso, a passagem da primeira à segunda infância $\mathrm{e}$ em outro, da segunda à terceira infância. O ciclo de vida assim festejado traça as diferentes etapas de uma dinâmica de constituição do ser social.

\section{Preparativos}

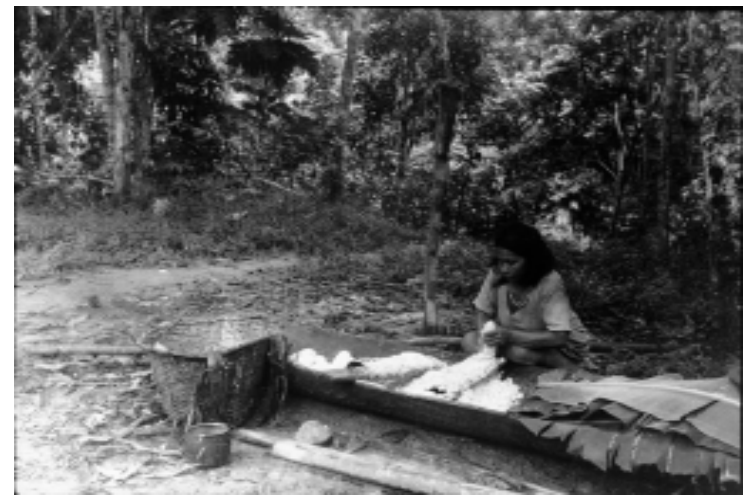

Quando a menina tem sua primeira menstruação, seus parentes dão início aos preparativos, convidando seus aparentados clânicos e providenciando material e alimentos para os três longos dias festivos. A mandioca e o peixe são preparados com antecedência (acima e ao lado à esquerda), assumindo "valor de uso ritual", notadamente na bebida "Pajauarú" (fermentado alcoólico da mandioca) e na carne moqueada que é distribuída entre os presentes.

Fibras extraídas de espécies vegetais, como o tururí e o buriti, são usadas na confecção das roupas e adereços cerimoniais (à direita).
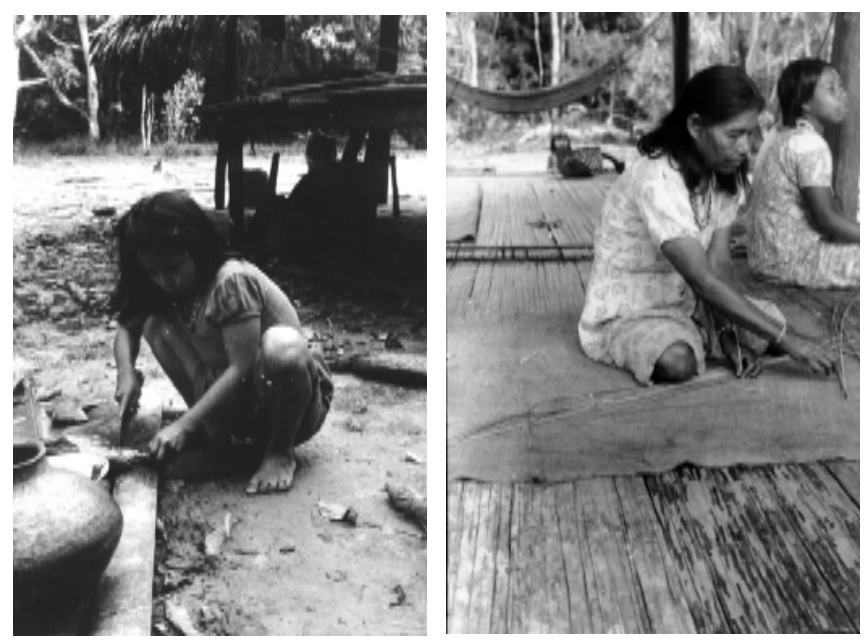


\section{Nominação}

No centro do local ritual os parentes preparam os ornamentos plumários para a paramentação dos iniciados. Uma faixa de pano de tururi esticada por uma corda horizontal recebe pintura e penas de diversos pássaros, formando o cocar para a cabeça (ao lado).

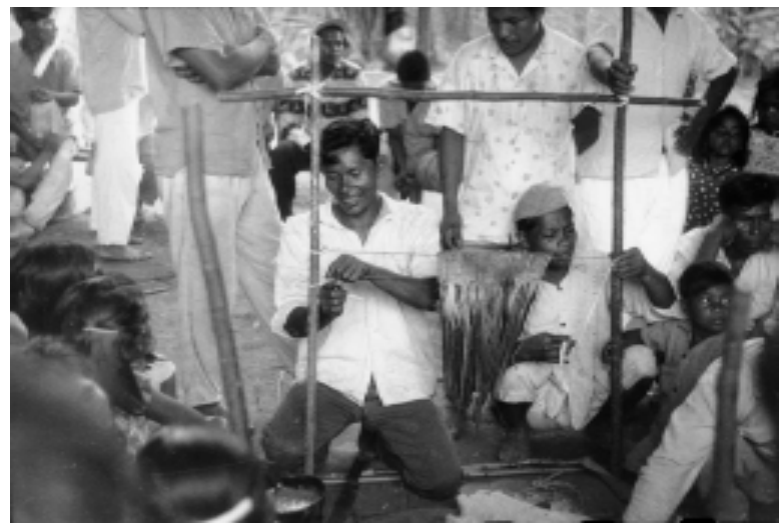

Abaixo a menina está sendo "pelada" pela técnica de arrancamento de cabelos enquanto o menino tem o seu cabelo cortado. As duas imagens representam a mesma cena vista sob ângulos opostos. Posteriormente o corpo receberá uma tintura de urucu, vermelha, sobre a qual será fixada plumagem de garça. Estes procedimentos rituais valem também para a "moça nova".
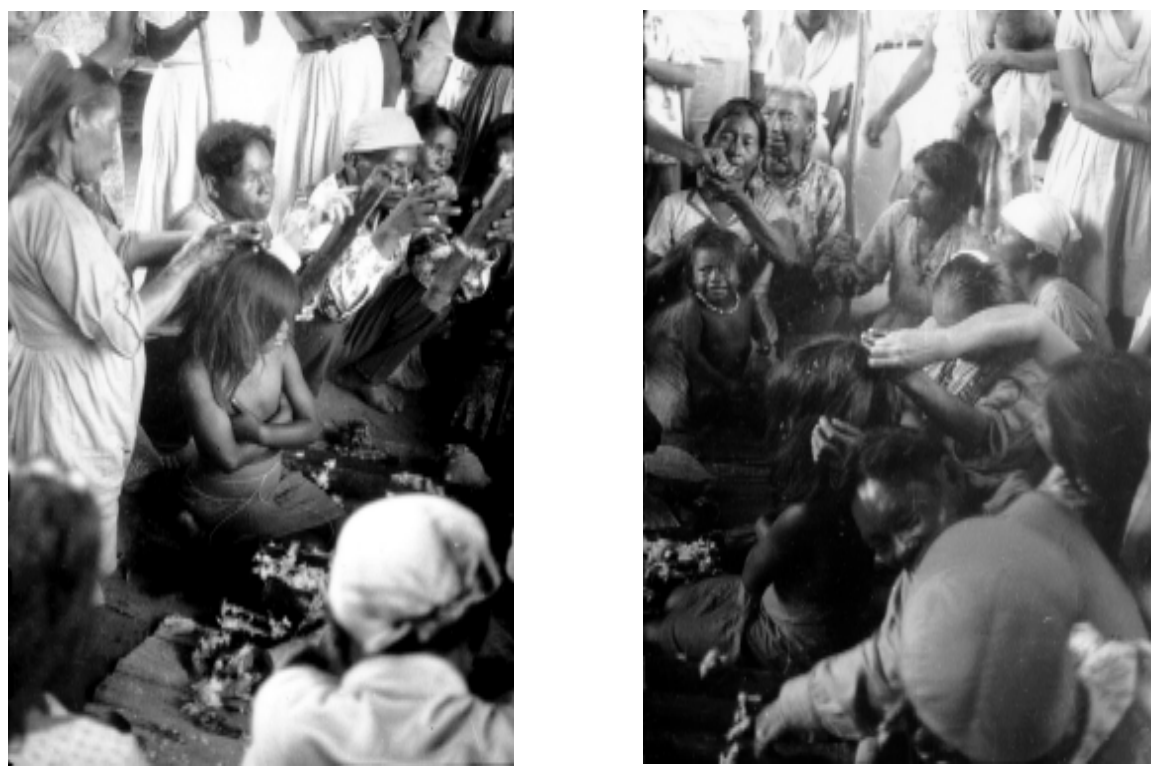


\section{"Moça Nova"}

Imagens do terceiro dia de festa. A iniciada já recebeu a paramentação e é conduzida pela mãe e por outros parentes do mesmo clã, ao som dos tambores, num lento vaievém, em direção ao centro da casa. É a dança cerimonial subseqüente à remoção da exclusão. Seus olhos estão cobertos de forma a ficarem

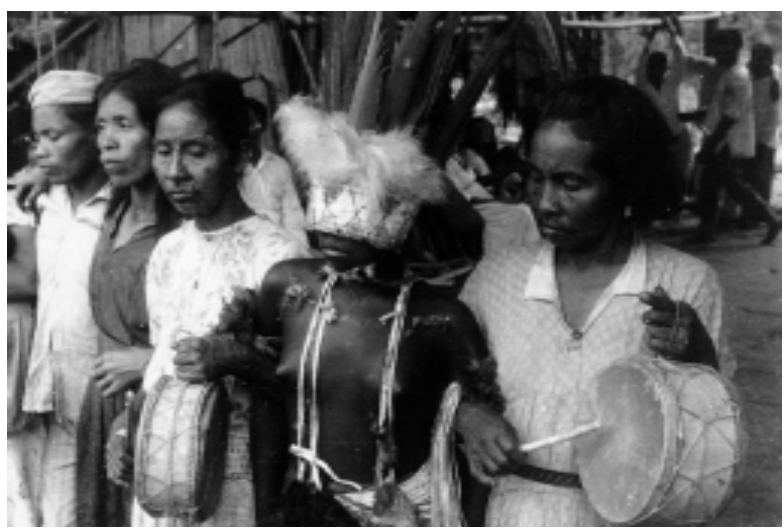
protegidos da luz do sol,

evitando o choque direto da claridade, excessivamente constrastante em face da penumbra que caracteriza sua anterior condição de reclusa. Além do cocar, pode-se ver os cordões de tururi branco enfeitados com plumagens variadas, pendendo de seus dois ombros até a cintura.
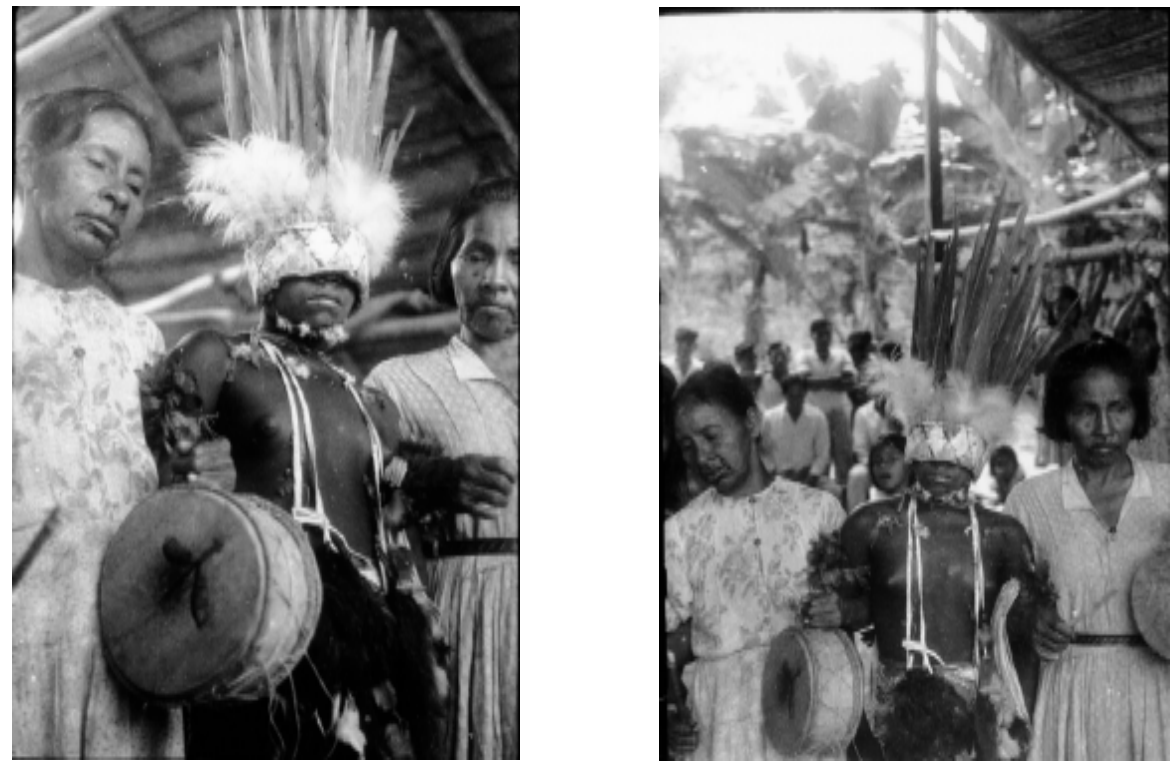

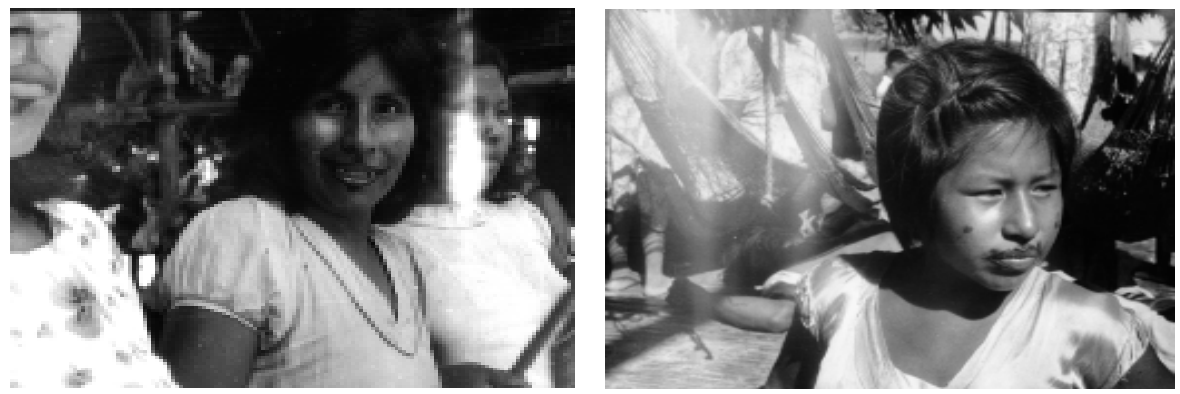

Estas imagens destacadas das fotografias mostram a pintura de jenipapo nas faces e em torno da boca, aplicada cerimonialmente sobre todos os participantes.
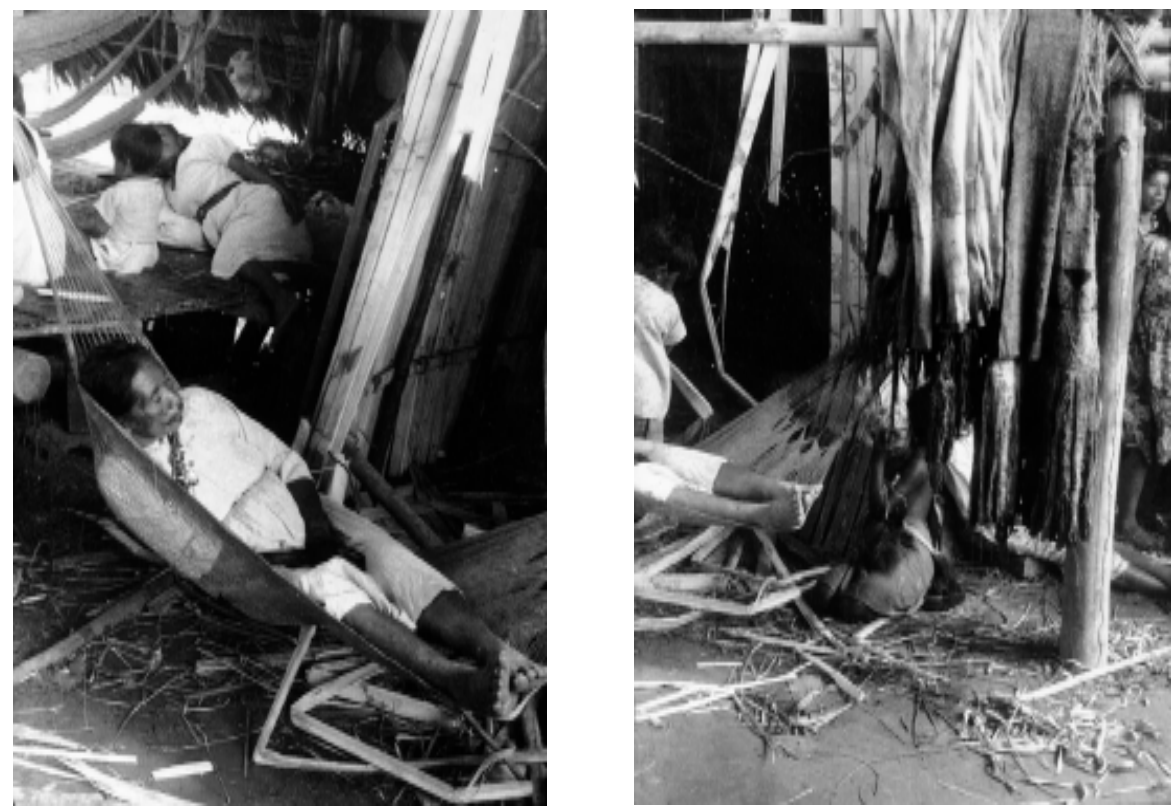

Acima à esquerda, a tia paterna dos iniciados num momento de repouso (ela aparece dançando nas imagens da página anterior). Ao lado da rede, o lugar cerimonial de resguardo da "moça nova", pequena cabana feita de cipós e tiras do buriti branco, foi aberto para que ela saísse em cortejo ritual. O "casulo" - para lembrar o canto que evoca a comparação com a borboleta em crisálida - foi quebrado e a jovem púbere saiu dali para ser feita "moça nova". Abaixo da rede, a menina do ritual de nominação descansa ajoelhada. Acima dela à direita, algumas roupas cerimoniais já dependuradas. Logo mais a festa será encerrada. 


\section{Outros momentos}

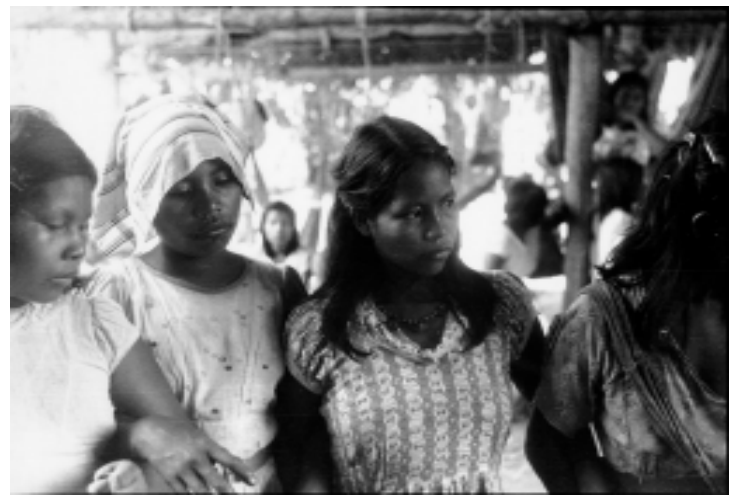

Cenas do interior da maloca Tükúna onde estava tendo lugar a cerimônia da "moça nova", quando convidados provenientes dos diversos clãs participavam ativamente do ritual.

Dentro da batida rítmica incessante, as danças e cantos, específicos de cada etapa festiva, são executados.

$\mathrm{Na}$ famosa dança do macaco-prego, por volta da meia noite (não há fotografias), é envergada uma máscara, confeccionada com entrecascas e devidamente pintada, equipada com um falo de cerca de meio metro, com o qual o dançarino investe zombeteiramente na direção dos convidados e contra o lugar de resguardo da moça.

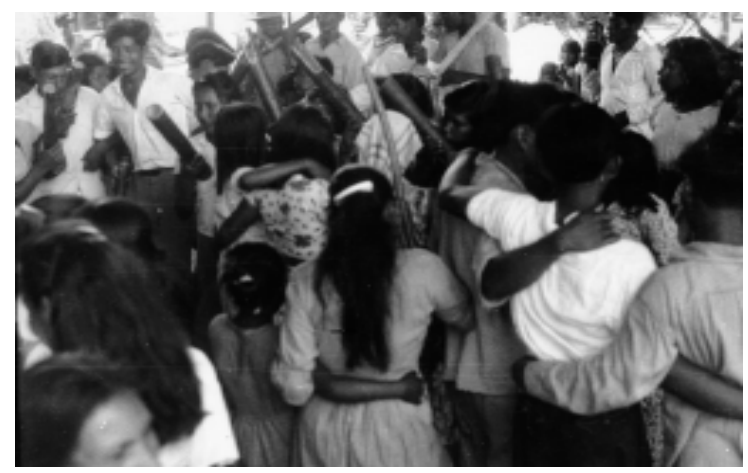

Uma vez terminadas as cerimônias, as máscaras (que são preparadas antecipadamente para a festa, representando determinadas entidades e forças naturais) são separadas dos trajes que as acompanham e empilhadas no centro da casa, sendo deixadas como

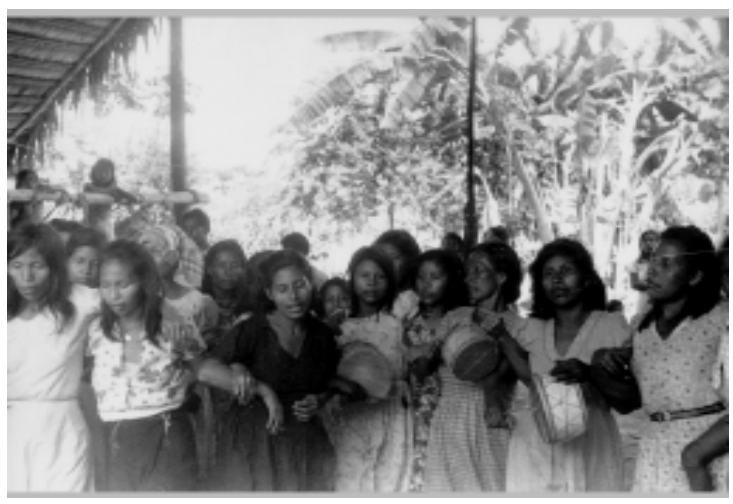
presente ao anfitrião e à mãe da moça. Antes que os convidados possam partir, a maloca deve estar limpa e arrumada.

Os três dias festivos são encerrados num cortejo em direção ao rio, onde todos se banham, sendo os iniciados submetidos pelos xamãs aos procedimentos rituais adequados, após o quê a vida cotidiana é então retomada. 


\section{Final}

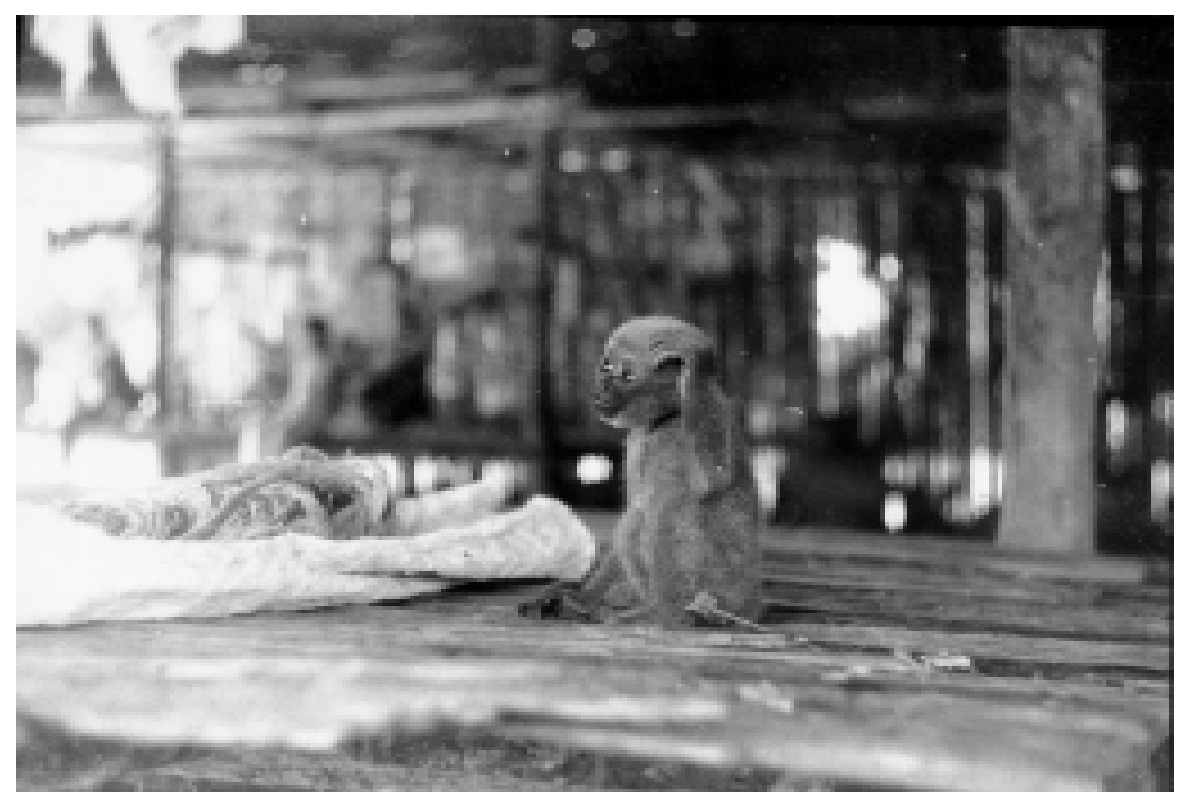

"Leibniz", pequeno mico-leão, foi assim batizado porque, com seus trinados, ironicamente lembrava ao antropólogo e ex-estudante de lógica um código de linguagem!

Este caderno foi elaborado como parte do trabalho de pesquisa em Multimeios/ Antropologia Visual Fotográfica, desenvolvido por João Martinho de Mendonça, sob orientação de Etienne Samain, com o apoio da FAPESP. Contou com a participação de Roberto Cardoso de Oliveira, que permitiu o uso de suas fotografias armazenadas no AEL/Unicamp e nos prestou valiosas informações para a pesquisa em curso.

\section{Bibliografia para aprofundamento}

\section{CARDOSODE OLIVEIRA, $R$.}

1983

"Aliança inter-clânica na sociedade Tükúna" e "Totemismo Tükúna?", in Enigmas e soluções: exercícios de etnologia e de crítica, Rio de Janeiro, Tempo Brasileiro. Caps. 3 e 5. 
$1964 \quad O$ índio e o mundo dos brancos: a situação dos Tükúna do alto Solimões, São Paulo, Difusão Européia do Livro, coleção Corpo e Alma do Brasil. (São Paulo, Pioneira, 1972. Brasília, Ed. Universidade de Brasília, 1981. Campinas, Ed. Unicamp, 1996.)

1959 "Tükúna/ 1959. Excertos de um diário de campo", comunicação apresentada na abertura do Encontro de pesquisadores Os Ticuna hoje: direções e perspectivas da pesquisa etnológica, de 25 a 27 de maio de 1998, no Museu Nacional da Universidade Federal do Rio de Janeiro (UFRJ), sob coordenação de João Pacheco de Oliveira Filho. Promoção: Projeto "Universo Ticuna: território, saúde e meio ambiente" (FINEP/ PPG-7).

GONZÁLES, H. A.

1995 Camacho. (recopilador) Mágutà, la gente pescada por y'oi, Colômbia, Tercer Mundo.

1996 Camacho. (recopilador) Nuestras caras de fiesta, Colômbia, Tercer Mundo. Transcripción en Tikuna por Federico José Huaines/Arara.

GRUBER, J. (org.)

1997 O livro das árvores: Ticuna, OGPTB, Benjamim Constant.

NIMUENDAJÚ, C.

1952 The Tukuna, Berkeley and Los Angeles, University of California Publications, American Archaeology and Ethnology, XLV.

OLIVEIRA FILHO, J. P. de

1988 "O nosso governo": Os Ticuna e o regime tutelar, São Paulo, Marco Zero (MCT/CNPq).

RONDON, Mal. C.F.

1953 Índios do Brasil, do norte do rio Amazonas, Rio de Janeiro, Conselho Nacional de Proteção aos Índios, Ministério da Agricultura, vol. III, pp.237-240 (prancha com 6 fotos e comentários nas legendas). 